\title{
KOMBINASI STATIC STRETCHING DAN PLYOMETRIC TRAINING LEBIH BAIK DARIPADA KOMBINASI STATIC STRETCHING DAN STRENGTH TRAINING DALAM MENINGKATKAN VERTICAL JUMP PADA PEMAIN VOLI
}

\author{
Dyah Esti Pranwengrum¹, I Dewa Putu Sutjana², Sugijanto ${ }^{3}$, Dewa Putu Gde Purwa \\ Samatra $^{4}$, Tjokorda Gde Bagus Mahadewa ${ }^{5}$, Luh Made Indah Sri Handari Adiputra ${ }^{6}$ \\ ${ }^{1}$ Program Studi Magister Fisiologi Keolahragaan Universitas Udayana, Denpasar \\ ${ }^{2,6}$ Departemen Ilmu Faal, Fakultas Kedokteran Universitas Udayana, Denpasar \\ ${ }^{3}$ Fakultas Fisioterapi Universitas Esa Unggul, Jakarta \\ ${ }^{4}$ Departemen Neurologi, Universitas Udayana, Denpasar \\ ${ }^{5}$ Departemen Ilmu Bedah, Universitas Udayana, Denpasar
}

E-mail : pranawengrum.dyah@gmail.com

\section{ABSTRAK}

Pendahuluan: Vertical jump merupakan komponen yang diperlukan dalam melakukan jump smash dan keterampilan melakukan service dalam permainan bola voli. Efisiensi melompat atau daya ledak ekstremitas bawah dapat menunjang pemain untuk mencetak skor. Tujuan penelitian: untuk membuktikan kombinasi static stretching dan plyometric training lebih baik daripada kombinasi static stretching dan strength training dalam meningkatkan vertical jump pada pemain voli. Metode: Penelitian ini menggunakan design experimental randomized pre-test and post-test two group design. Penelitian dilakukan di UKM Bola Voli STIKES Ngudia Husada Madura. Sampel penelitian sebanyak 18 orang yang dibagi menjadi 2 kelompok secara acak, masing-masing kelompok berjumlah 9 orang. Kelompok I diberikan kombinasi static stretching dan strength training sedangkan Kelompok II diberikan dengan kombinasi static stretching dan plyometric training. Perlakuan dilakukan 3 kali seminggu selama 6 minggu dengan evaluasi menggunakan sargent jump test (SJT). Hasil penelitian: Uji statistik menggunakan paired-samples $t$-test pada Kelompok I dengan rerata

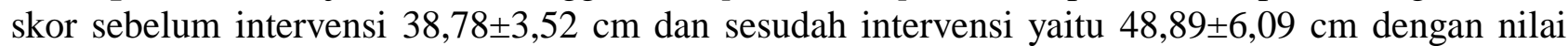


intervensi 54,11 $\pm 2,66 \mathrm{~cm}$ dengan nilai $\mathrm{p}<0,001$. Dapat disimpulkan terjadi peningkatan vertical jump yang bermakna padi setiap kelompok. Uji beda hipotesis antara Kelompok I dengan Kelompok II menggunakan uji independent-samples $t$-test diperoleh nilai $\mathrm{p}=0,021$. Simpulan: Kombinasi static stretching dan plyometric training lebih baik dalam meningkatkan vertical jump pada pemain voli dari pada kombinasi static stretching dan strength training.

Kata kunci : Static stretching, strength training, plyometric training, vertical jump

\section{COMBINATION OF STATIC STRETCHING AND PLYOMETRIC TRAINING IS BETTER THAN COMBINATION OF STATIC STRETCHING AND STRENGTH TRAINING IN INCREASING VERTICAL JUMP IN THE VOLLEYBALL PLAYER}

\section{ABSTRACT}

Background: Vertical jump is an essential component in jump smashes and service skills in volleyball games. The efficiency of the jump or explosive power of the lower limb can support the 
player to score. Aim: to prove that the combination of static stretching and plyometric training is better than the combination of static stretching and strength training in increasing vertical jumps performance in volleyball players. Method: This was experimental study with randomized pre-test and post-test two group design. Participants for this study was collegiate volleyball player of STIKES Ngudia Husada Madura. Eighteen collegiate participate in this study and randomly divided into 2 groups with each group consist of 9 people. Group I was given a combination of static stretching and strength training while Group II was given a combination of static stretching and plyometric training. The treatment done 3 times a week for 6 weeks with evaluation using the sargent jump test (SJT). Result: Statistical analysis using paired-samples t-test in Group I revealed a mean score before intervention $38.78 \pm 3.52 \mathrm{~cm}$ and after the intervention is $48.89 \pm 6.09 \mathrm{~cm}$ with p value $=0.001$. While in Group II mean scores before intervention 37, $11 \pm 4.01 \mathrm{~cm}$ and after the intervention $54.11 \pm 2.66$ $\mathrm{cm}$ with $\mathrm{p}$ value $<0.001$. These results indicate that in each group there was a significant increase in vertical jump performance. Hypothesis different test between Group I and Group II using the independent-samples t-test obtained $\mathrm{p}$ value $=0.021$. Conclusion: The combination of static stretching and plyometric training is better than the combination of static stretching and strength training at increasing vertical jumps performance in volleyball players.

Keywords : Static stretching, strength training, plyometric training, vertical jump

\section{PENDAHULUAN}

Permainan bola voli adalah olahraga yang melibatkan dua tim dan setiap tim terdiri dari enam orang. Tujuan dari permainan ini adalah untuk mencetak skor di area lawan.

Gerakan-gerakan pada permainan bola voli memerlukan kekuatan otot tungkai yang memadi, terutama untuk smashing. Pemain bola voli harus memiliki kemampuan vertical jump yang baik agar dapat melompat dan mencetak skor. ${ }^{1}$ Vertical jump adalah kemampuan seseorang untuk meloncat kearah vertical setinggi-tingginya. $^{2}$

Hasil studi pendahuluan yang dilakukan terhadap 30 orang pemain bola voli putra pada unit kegiatan mahasiswa STIKES Ngudia Husada Madura dengan rentang usia 18-20 tahun. Didapatkan data bahwa sebanyak 30\% dari pemain tersebut memiliki kemampuan vertical jump pada batas rata-rata.

Stretching dilakukan sebagai pemanasan sebelum melakukan latihan, dapat mengurangi kekakuan pasif dan meningkatkan ROM selama latihan. Static stretching yang diberikan pada otot ekstremitas bawah saat sebelum melakukan latihan juga dapat membantu meningkatkan performa vertical jump. ${ }^{3}$
Plyometric training adalah program latihan yang melibatkan kontraksi eksentrik dan konsentrik dengan waktu seceoatcepatnya. . ${ }^{4}$

Latihan kekuatan adalah latihan prosedur sistematis otot atau kelompok otot yang mengangkat, dan mengendalikan beban berat (resistansi) untuk jumlah repetisi yang relatif rendah atau dalam waktu singkat. Adaptasi yang paling umum untuk latihan ketahanan berat adalah peningkatan kapasitas otot yang menghasilkan kekuatan maksimum, yaitu peningkatan kekuatan otot. ${ }^{5}$

\section{METODE PENELITIAN}

Penelitian ini adalah experimental pre test and post test two group design. Kelompok 1 diberikan perlakuan kombinasi static stretching dan strength training, sedangkan kelompok 2 diberikan perlakuan kombinasi static stretching dan plyometric training. Pengukuran vertical jump menggunakan sargent jump test (SJT).

Penelitian ini dilakukan pada tim bola voli laki-laki STIKES Ngudia Husada Madura, pada bulan Januari-Februrari 2020. Penelitian berlangsung selama 6 minggu. Jumlah sampel 
untuk masing-masing kelompok adalah 9 orang.

\section{HASIL PENELITIAN}

\section{Karakteristik Subjek Penelitian}

Berdasarkan uji statistic, usia lebih dari 19 tahun merupakan frekuensi terbanyak baik di Kelompok I maupun pada Kelompok II. Rentang usia tersebut merupakan usia sample mahasiswa semester satu, tiga dan lima.

Data karakteristik nilai SJT pre Intervensi menunjukkan bahwa rentang skor $31-40 \mathrm{~cm}$ merupakan frekuensi terbanyak pada kedua kelompok. Sedangkan mayoritas tinggi badan untuk kedua kelompok adalah 171-180 $\mathrm{cm}$ dan mayoritas rentang berat badan adalah $51-60 \mathrm{~kg}$.

\section{Uji Normalitas dan Homogenitas}

Kedua kelompok memiliki distribusi data normal $(\mathrm{p}>0,05)$ data bersifat homogen ( $p>0,05)$. Berdasarkan uji tersebut, maka uji untuk pengujian hipotesis adalah uji statistic menggunakan uji parametrik.

\section{Uji Beda Rerata Skor Sargent Jump Test}

Berdasarkan perhitungan statistik dengan Paired-Sample t-Test, didapatkan hasil yaitu nilai $\mathrm{p}=0,001 \quad(\mathrm{p}<0,05)$. Dapat disimpulkan bahwa kombinasi static stretching dan strength training meningkatkan vertical jump. Selain itu, pada kelompok I terjadi peningkatan vertical jump $26 \%$.

Sedangkan pada Kelompok II, didapatkan nilai $\mathrm{p}<0,001(\mathrm{p}<0,05)$. Dapat kombinasi static stretching dan plyometric training dapat meningkatkan vertical jump. Pada kelompok ini terjadi peningkatan vertical jump $45,8 \%$.

\section{Uji Komparasi Skor Sargent Jump Test Sebelum dan Sesudah Latihan antar kelompok}

\section{Tabel 1}

\begin{tabular}{ccc}
\multicolumn{3}{c}{ Independent Sample t-test } \\
\hline \multirow{3}{*}{ Kelompok } & $\begin{array}{c}\text { Sebelum } \\
\text { Intervensi }\end{array}$ & $\begin{array}{c}\text { Sesudah } \\
\text { Intervensi }\end{array}$ \\
\cline { 2 - 3 } & rerata \pm SB & rerata \pm SB \\
\hline I & $38,78 \pm 3,528$ & $48,89 \pm 6,092$ \\
II & $37,11 \pm 4,014$ & $54,11 \pm 2,667$ \\
\hline$p$ & 0,594 & 0,021 \\
\hline
\end{tabular}

Hasil uji komparasi skor sargent jump test sebelum dan sesudah latihan didaptkan nilai $\mathrm{p}=0,021(\mathrm{p}<0,05)$. Dapat diimpulkan kombinasi static stretching dan plyometric training lebih baik daripada kombinasi static stretching dan strength training dalam meningkatkan vertical jump pada pemain voli.

\section{PEMBAHASAN}

Kombinasi static stretching dan strength training dapat meningkatkan vertical jump pada pemain voli.

Penelitian ini sesuai oleh Christou et al. yang menunjukkan bahwa kombinasi static stretching dan strength training dapat meningkatkan vertical jump pada pemain sepak bola yang diberikan latihan selama 6 minggu. Pada penelitian tersebut terjadi peningkatan power tungkai bawah sebanyak $58 \%$ sehingga mampu meningkatkan performa vertical jump. ${ }^{6}$

Peningkatan performa vertical jump juga ditemukan pada studi Wong et al. Dalam studinya, kombinasi static stretching dan strength training yang diberikan selama 12 minggu dapat meningkatkan kekuatan dan power tungkai bawah pada pemain sepak bola. $^{7}$

Perubahan yang terjadi akibat dari strength training adalah meningkatan rekrutmen motor unit, sinkronisasi motor unit dan adaptasi morfologis (struktural), seperti peningkatan luas penampang. Menurut Seynnes et al., peningkatan kinerja dapat dijelaskan baik oleh peningkatan area crosssectional serta oleh adaptasi neuromuskuler, seperti meningkatkan koordinasi intramuskuler dan intermuskuler. ${ }^{8}$

Menurut studi yang dilakukan oleh Del Veccio et al., strength training yang dilakukan selama empat minggu akan meningkatkan produksi power otot. Pada saat dilakukan strength training, terjadi peningkatan rekrutmen motor unit di dalam otot. Peningkatan rekrutmen tersebut akan menyebabkan adaptasi neural yang akan menyebabkan perubahan input sinaptik ke 
kumpulan neuron motorik untuk adaptasi neuron motorik intrinsik. ${ }^{9}$

Strength training akan menurunkan ambang batas rekrutmen motor unit sehingga terjadi peningkatkan laju pelepasan motor unit. Hal tersebut akan menyebabkan peningkatan gaya yang diproduksi oleh otot sehingga power pada otot juga akan meningkat, Peningkatan power otot akan berkontribusi untuk meningkatkan performa vertical jump. ${ }^{10}$

\section{Kombinasi static stretching dan plyometric training dapat meningkatkan vertical jump pada pemain voli.}

Plyometric training dapat menurunkan sensitivitas golgi tendon organ (GTO) yang memungkinkan otot untuk menghasilkan kekuatan otot yang lebih besar dengan sistem muskuloskeletal yang dapat mentoleransi peningkatan beban kerja tanpa penembakan GTO. Plyometric training kemampuan neuromuskuler dan membuat gerakan lebih otomatis selama latihan. Pada keadaan ini, pola motorik akan lebih kuat dan menciptakan otomatisasi aktivitas. Hal tersebut akan meningkatkan efisiensi saraf dan meningkatkan kinerja neuromuskuler. ${ }^{11}$

Plyometric training mempengaruhi kinerja stretch- shortening cycle (SSC). SSC adalah fungsi neuromuskuler yang penting untuk menghasilkan power. SSC terdiri dari fase eksentrik (peregangan), amortisasi, dan konsentris (pemendekan). Pada fase eksentrik bagian otot dan tendon akan memanjang, energi elastis potensial pada otot dan tendon disimpan dari fase pemanjangan dan fase kontraksi konsentris. Power diproduksi melalui pelepasan energi elastis yang ditransfer dari kontraksi ekstentrik. Amortisasi adalah waktu antara akhir fase pemanjangan dan awal fase konsentris. Ketika jeda waktu tersebut, jumlah energi elastis yang disimpan dalam otot dan tendon berkurang. Akibatnya, kemampuan neuromuskuler untuk menghasilkan kekuatan dan kekuatan dapat berkurang. Dengan dilakukan plyometric training, fase amortisasi ini akan lebih pendek sehingga power akan tercipta dalam waktu yang singkat dan efisien. ${ }^{12}$
Kombinasi static stretching dan plyometric training lebih baik daripada kombinasi static stretching dan strength training dalam meningkatkan vertical jump pada pemain voli.

Kombinasi static stretching dan plyometric training dapat memberikan efek berupa stimulasi meningkatkan power, kecepatan rata-rata, peningkatan kekuatan puncak otot dalam rangkaian komponen elastis, dan kemampuan untuk mengafirmasi refleks peregangan pada otot. ${ }^{4}$

Pada saat fase eksentrik, jumlah daya ledak yang dihasilkan lebih besar daripada saat fase isomterik. Ketika otot sedang ekstenrik maksimal, jumlah daya ledak yang diproduksi adalah 10-40 persen daripada kontraksi isometrik. Hal tersebut disebabkan karena rangkaian komponen elastis dan komponen elastis parallel teregang dan menghasilkan daya ledak yang besar. ${ }^{4}$

Plyometric training yang dilakukan dengan intensitas tinggi diatas 80 persen akan membantu rekrutmen fast twitch fiber yang sangat krusial bagi prduksi daya ledak. Hal tersebut dikarenakan fast twitch fiber merespon dengan baik latihan dengan intesitas cepat dan tinggi seperti plyometric training. ${ }^{4}$

Faktor lain yang mempengaruhi produksi daya ledak adalah keseimbangan. Menurut Hammami et al., dengan diberikannya plyometric training, akan mempengaruhi kontrol neuromuskuler dan kontrol postural yang menyebabkan keseimbangan tubuh akan lebih besar. Ketika keseimbangan lebih besar, maka akan dapat membantu terciptanya daya ledak yang lebih besar serta gerakan yang lebih cepat. ${ }^{13}$

Sedangkan menurut studi yang dilakukan MacDonald, strength training dapat meningkatkan sinkronisasi motor unit dan adaptasi morfologis struktural. Hal tersebut akan menyebabkan hipertrofi otot yang terjadi peningkatan kekuatan otot. Seiring dengan terjadinya peningkatam kekuatan otot, maka daya ledak yang diciptakan juga akan besar. Namun perubahan struktural pada strength training dapat menurunkan adaptasi neural dan tidak mempengaruhi SSC sehingga, dibutuhkan waktu yang lebih untuk menghasilkan daya ledak otot. ${ }^{14}$ 


\section{KETERBATASAN PENELITIAN}

1. Penelitian ini baru menunjukkan peningkatan vertical jump untuk jangka pendek saja. Pada penelitan selanjutnya diharapkan untuk menambah durasi penelitian agar dapat melihat efektifitas latihan jangka panjang.

2. Peneliti tidak bisa mengontrol aktivitas atau faktor lain yang dapat mempengaruhi hasil penelitian. Unutk penelitan selanjutnya diharapkan untuk mengontrol variable sehingga mendapatkan hasil yang akurat.

\section{SIMPULAN}

Kombinasi static stretching dan plyometric training lebih baik daripada kombinasi static stretching dan strength training dalam meningkatkan vertical jump pada pemain voli

\section{DAFTAR PUSTAKA}

1. Dearing, J. 2018. Volleyball Fundamentals (Sports Fundamentals) Second Edtiton. Chichago. Human Kinetics.

2. Ostojic, M. S., Marko S., Zlatko A. 2010. Vertical Jump As A Tool In Assessment Of Muscular Power And Anaerobic Performance. Med Pregl. Vol : 63, Hal : 371-375.

3. De Souzaa L. M. L., Gabriel A. P., Isabella L. E., Rodrigo D., Marianna de F. M., Humberto M., Vicente P. L. 2016. Vertical jump performance after passive static stretching of knee flexors muscles. Vol : 51

4. Davies, G., Bryan L. R., Robert M. 2015. Current Concepts Of Plyometric Exercise.The International Journal of Sports Physical Therapy. Vol :10 (6), Hal : 760-787

5. Kisner, C. and Colby, L. A. 2014. Therapeutic Exercise 6th edition. Philadelphia.FA Davis Company.

6. Christou M., Smilios I., Sotiropoulos K., Volaklis K., Pilianidis T., Tokmakidis S.P. 2012. Effects of resistance training on the physical capacities of adolescent soccer players. J Strength Cond Res. Vol :20, Hal :78-79

7. Wong P.L., Chamari K., Wisloff U. 2010. Effects of 12-week on-field combined strength and power training on physical performance among U-14 young soccer players. J Strength Cond Res. Vol: 24(3), Hal :644-652

8. Seynnes, O. R., Erskine R. M., Maganaris C. N., Longo S., Simoneau E. M., Grosset J. F., and Narici M. V. 2009. Traininginduced changes in structural and mechanical properties of the patellar tendon are related to muscle hypertrophy but not to strength gains. Journal of Applied Physiology. Vol :107(2), Hal : 523-530

9. Del Vecchio, A., Casolo, A., Negro, F., Scorcelletti, M., Bazzucchi, I., Enoka, R., Felici, F. and Farina, D. 2019. The increase in muscle force after 4 weeks of strength training is mediated by adaptations in motor unit recruitment and rate coding. J Physiol, Vol :597, Hal : 1873-1887

10. Farina D., Negro F., Muceli S. and Enoka R.M .2016. Principles of motor unit physiology evolve with advances in technology. Physiology. Vol : 31, Hal : 8394.

11. Van Hooren B., Bosch F. 2016. Influence of muscle slack on high-intensity sport performance: a review. Strength Cond J. Vol: 38, Hal:75-87

12. Kang, S. 2018. Difference of neuromuscular responses by additional loads during plyometric jump. Journal of Exercise Rehabilitation. Vol: 14(6), Hal :960-967

13. Hammami, R., Chaouachi, A., Makhlouf, I., Granacher, U., and Behm, D. G.2016. Associations between balance and muscle strength, power performance in male youth athletes of different maturity status.

Pediatr. Exerc. Sci. 28, 521-534

14. MacDonald C.J., Lamont H.S., Garner J.C, Jackson K. 2013. A comparison of the effects of six weeks of traditional resistance training, plyometric training, and complex training on measures of power. Journal of Trainology. Vol : 2, Hal :13-18 